\title{
O Olhar - Fazer Interdisciplinar no Atendimento às Vítimas de Violência Doméstica no Âmbito Policial: Estudo Preliminar. ${ }^{1} 2$
}

\section{Interdisciplinarity in Giving Assistance to Victims of Domestic Violence in The Political Scope: Preliminary Study.}

\section{Michael Hermann ${ }^{3}$}

Artigo

Original

Palavras-chaves: Interdisciplinaridade; Violência Doméstica; Segurança Pública

\section{Resumo}

Este trabalho foi desenvolvido durante uma experiência profissional dentro de uma delegacia de polícia - instituição esta que, no final da década de 90, passou por várias reformas não só dentro do seu aparato administrativo, mas na sua concepção de como a mesma vê a violência e suas causas. Os novos profissionais policiais capacitados e preparados vêm com esta concepção, porém, ainda maculada com as velhas práticas repressoras e burocráticas da própria instituição. Comessa mudança, vemàinclusão dos profissionais não policiais, constituídos em sua maioria por assistentes sociais, psicólogos e pedagogos, que primeiramente não são incorporados nos quadros da polícia estadual, mas fazem parte de um projeto que gerou tais modificações dentro do aparato da segurança pública no Estado do Rio de Janeiro. Tal projeto se denomina Programa Delegacia Legal, em que o grupo gestor do mesmo não quer que o projeto seja passageiro, fruto de um momento conjuntural e político, mas quer que ele faça parte do organograma que constituí o sistema de segurança pública de fato. Dentro da "delegacia legal" há a constituição de uma equipe de profissionais - policiais ou não - prontos para atender a população que necessita de demandas que ultrapassam a natureza criminal. As demandas que fogem ao objeto do inquérito policial são ainda desprezadas por muitos profissionais policiais, e gera conflitos com os demais profissionais não policiais - que são capacitados a atenderem tais demandas. Este trabalho expõe as formas de como estas equipes são constituídas dentro de uma delegacia de polícia, e mostra como é possível formar uma equipe - constituida de profissionais policiais e não policiais - que trabalhe de uma forma interdisciplinar, atendendo assim a todas as demandas e encaminhamentos posteriores, mesmo com todas as dificuldades institucionais e com a correlação de forças presente.

Key words: Interdisciplinarity; Domestic Violence; Public Security.

\section{Abstract}

This work was developed during a professional experience inside a police station. In the late 90s, such institution underwent some reforms that were both administrative ones and about its conception of violence and its causes. The new trained police officers already have this conception; however, it is still linked with repressive and bureaucratic practices of the institution itself. With this change, there is the inclusion of professionals who are not police officers, being most of them social assistants, psychologists and educators, which are not incorporated in the state police at first, but they are part of a project that has made such changes in the public security in the state of Rio de Janeiro. This project is called "Programa Delegacia Legal” (Legal Police Station Program) in which the management group does not want the project to be temporary as a result of the conjectural and political moment, but the group wants it to be part of the organogram that, in fact, constitutes the public security system. Inside the Delegacia Legal there is a team of professionals - police officers or not - ready to deal with people who need what is beyond criminal nature. The demands that have nothing to do with the police enquiry are disregarded by many police officers, which promotes disagreement with the other professionals who are capable of dealing with such demands. This work explains how teams are formed within a police station and shows how a team - being formed by professional police officers or not - can work in an interdisciplinary way, assisting all that follows, even with all the institutional difficulties and actual correlation of forces.

${ }_{1}$ Tal artigo foi resultado de um estudo monográfico para a obtenção de título da Especiolização em Atendimento a Criança e Adolescente Vítima de Violência Doméstica pela PUC - Rio de Janeiro, em 2004. O trabalho foi desenvolvido durante a inserção do autor, como profissional não policial, no Programa Delegacia Legal, lotado em uma das DP's situadas na Baixada Fluminense, no Estado do Rio de Janeiro, no período compreendido entre 2004 a 2005.

${ }^{2}$ Tal estudo está tendo continuidade em um projeto de pesquisa e extensão coordenado pelo NEPSSI - Núcleo de estudos e Pesquisas em Serviço Social e Interdisciplinaridade - sob a chancela da UNIME Salvador. O projeto se intitula "Serviço Social e Interdisciplinaridade presentes no Campo Sócio-Jurídico no Estado da BA", que tem por objetivo não só levantar e analisar o processo de trabalho dos assistentes sociais inseridos neste campo sócio-ocupacional, mas de tentar visualizar a concepção de trabalhos de natureza interdisciplinar na resolução das demandas materializadas pelos usuários que recorrem a este espaço já mencionado.

${ }^{3}$ Assistente Social pela Universidade Federal de Juiz de Fora - UFJF, Especialista em Violência Doméstica e Urbana pela PUC Rio de Janeiro e Mestrando da Pós - Graduação Strictu Sensu em Políticas Sociais e Cidadania pela Universidade Católica do Salvador (UCSal)- Salvador/BA, Membro associado da NET- Núcleo de Estudos do TrabalhoPPGPSC/UCSal e Membro do Núcleo de Pesquisa e Estudos sobre Juventude, Identidades, Cidadania e Cultura - PPGPSC/UCSal (email: asmichael@uol.com.br) 


\section{Violência Doméstica como Cotidiano no Âmbito Policial}

O trabalho a ser descrito foi feito durante entre os anos de 2004 a 2005, quando foram observadas várias experiências multi e interdisciplinares no atendimento às vítimas de violência doméstica no âmbito policial. A inserção deste breve estudo nas delegacias de polícia (DP's) foi feita pelo Programa Delegacia Legal, com a inclusão de profissionais não policiais ${ }^{4}$, que veio em um momento político vertical e pontual para dar maior qualidade operacional e organizacional dentro dos quadros da PCERJ ${ }^{5}$. O Programa em questão foi colocado na gestão do Governo de Anthony Garotinho - no ano de 1999 que modificou a estrutura administrativa das antigas delegacias com um sistema moderno de informatização; interligando as Delegacias Policiais; fornecendo maiores informações para elaboração de um Registro de Ocorrência - RO; mudando o meio, o modo e a prática diária de um plantão policial; interligando com a rede de atendimento sócio-assistencial presente em todo Estado do Rio de Janeiro.

O tema sobre violência doméstica, durante a preparação do corpo policial, dentro da Academia de Polícia, é visto como um fato atípico, diferente dos processos e flagrantes mais corriqueiros que envolvem homicídios, sequestros, crimes contra o patrimônio e tráfico de entorpecentes.

Embora nos últimos anos, nota-se o despertar de consciência e de disposição da sociedade em reagir à violência infantojuvenil. Por meio dos meios de comunicação, um grande contingente de policiais não se sente preparado e sensível para lidar com o tema. O preconceito, o medo e o não preparo fazem do processo interrogatório e investigativo de um abuso cometido, para formalizar o inquérito policial uma nova revitimização da criança/ adolescente abusada. Se os policiais, durante o seu processo de formação na Academia de Polícia, estudam o ECA e os sistemas de proteção voltados a tais vítimas, não implementam de fato tais encaminhamentos na sua rotina de formulação do inquérito.

Embora haja a existência de DEAM's e de DPCA's, há uma resolução que a violência perpetrada contra a mulher, ou a criança e o adolescente pode ser denunciada em qualquer DP mais próxima da residência da vítima. Na prática, a vítima - sobretudo a mulher - é "bicada" para a delegacia especializada, que na maioria das vezes fica mais distante e difícil o transporte, que é uma das carências em algumas regiões no Estado do RJ. Quando tal demanda chega até o Balcão de Atendimento, onde se alocam os profissionais não policiais, as mulheres abusadas manifestam no seu discurso uma série de conflitos familiares que traduzem um ambiente de alto risco para a mesma e a sua prole. Muitas vezes são encaminhadas para os policiais responsáveis que, não tendo formação específica, desqualificam o seu discurso, encaminhando a mesma ou para uma DEAM ou de volta para a sua residência. Não se configurando o RO - Registro de Ocorrência. Subsequentemente, isso acarreta na existência do sub-registro, que compromete a base para a formulação de novas políticas de ações na área de Segurança Pública dentro do Estado do Rio de Janeiro, ou seja, não demonstram a realidade de fato, acarretando na ineficácia dessas ações. Em notas e noticiários de jornais dos Estados de Minas Gerais e Bahia, tal sub-registro é denotado devido a localização e a acessibilidade de tais delegacias especializadas.

No caso de uma DEAM - que fez parte deste estudo - era responsável por $65 \%$ da área cicunscricional de toda a Baixada Fluminense quanto ao levantamento, atendimento, investigação criminal e apuração de denúncias quando há violência contra a mulher. E mesmo assim, há relatos de "bicos" ocorridos em seu próprio espaço, ou seja, os dados não correspondem a realidade total. $\mathrm{A}$ violência conjugal parece ser mais elevada. $\mathrm{O}$ agressor da mulher dentro de casa muitas vezes é o "eleito" para compartilhar uma vida em comum com a mesma, que exerce o seu poder dentro de um microcosmo, onde no

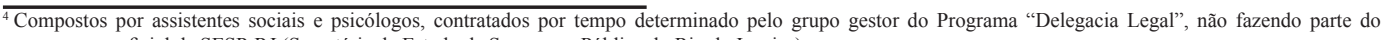
organograma oficial da SESP-RJ (Secretária de Estado de Segurança Pública do Rio de Janeiro). ${ }^{5}$ Polícia Civil do Estado do Rio de Janeiro.

${ }^{6}$ ACADEPOL.

${ }^{7}$ Estatuto da Criança e do Adolescente (Lei no8069/90).

${ }^{8}$ Apenas a parte criminológica que conta dentro de um inquérito, segundo Foucault(1977).

${ }^{9}$ Delegacia Especializada de Atendimento à Mulher. Concepção de combate legal e institucional à violência cometida contra a mulher. Iniciou-se nos anos 80 , quando



${ }^{10}$ Delegacia de Proteção à Criança e ao Adolescente.

${ }^{11}$ Delegacia de Policia.

${ }^{12}$ Durante o período da pesquisa dentro do Programa "Delegacia Legal", observou-se que o tão famoso "bico"- jargão utilizado pelos profissionais policiais - possui como vítimas preferenciais as mulheres vítimas de violência doméstica. Muitas até desistiram de fazer a denúncia depois de passaram por esse descrédito. 
macrocosmo, o algoz se torna tão vítima quanto as suas vítimas dentro do lar. Muitas vezes, a prole é tão vítima quanto a mãe/esposa. A violência conjugal, quando há a existência dos filhos, torna-se violência intrafamiliar, onde o patriarcado arcaico mostra todo o seu poder.

A sociedade, nestes tempos ainda contemporâneos, só legitima dois tipos de mulheres: a mulher-mãe, mulher-esposa, que é passiva e tudo compreende, e a mulher sensual, que gosta e sente prazer. O homem é o ser privilegiado que passeia por entre estes dois mundos. Apesar de parecerem dois mundos diferentes, e, para alguns, até dicotômicos, nesses dois tipos, a mulher é subserviente ao homem. O primeiro tipo é encontrado em casa, como esposa e mãe, e o segundo, na rua, como "mulher da vida", prostituta, que seduz o homem.

A partir disso,"a violência seria, portanto, toda e qualquer ação que toma o outro como coisa, objeto desprovido de desejo, de autonomia, de auto-determinação. (...). A violência é a reafirmação do corpo masculino e a negação do desejo feminino" (Cromberg, 2001,44)

A violência contra a mulher é a expressão clara e cruel de discriminação que vem sofrendo ao longo dos tempos. Discriminação essa que se traduz em tudo aquilo que é visto pela sociedade como "menor". É o fenômeno da "Síndrome do Pequeno Poder", que atua sobre as pessoas que não se enquadram no modelo de poder: a mulher, o negro, a criança e o pobre. E, ao contrário, o detentor do poder é branco, macho, rico e adulto. Assim, a menina pobre e negra é considerada como a criatura "menor" da sociedade, e assim, é a de todas a mais discriminada.

A violência contra a mulher, nesse sentido, é muito ampla, e vai além das paredes de sua casa. Ela começa a ser discriminada como cidadã por práticas institucionais presentes em nossa sociedade. Ao longo do tempo, isso vem sendo disseminado, passando de ser considerado comum, para se perceber como problema social. No Brasil, no final dos anos 70, a partir de movimentos feministas contra assassinatos cometidos contra a mulher em nome da "defesa da honra", vieram à tona questões como a opressão da mulher na sociedade brasileira, em vários aspectos, além da violência conjugal, como a discriminação no trabalho e o desrespeito ao corpo da mulher.

A violência conjugal é um hábito no cotidiano do casal, que garante ao homem, a cada passo, a cada atitude, um pouco mais de poder sobre a sua mulher. E tal fato é legitimado - mesmo que nebulosamente pelo corpo que constitui a instituição policial quando se desqualifica a queixa da mulher vítima de violência dentro do espaço policial. Há a necessidade de se mudar a banalização de tal violência do cotidiano dos lares.

Além disso, há alguns fatores importantesquesãorelevantescomoafinalidade e a disponibilidade de tais profissionais não policiais dentro do espaço - conflituoso - da delegacia de polícia: (a) como profissionais do "acolhimento" no espaço policial, sendo os primeiros a atenderem tais vítimas, buscando a não continuidade do processo de re-vitimização, subsidiando no resgate de seus direitos mais fundamentais, para - depois procurar a subsequente resolução da parte criminológica de fato, cujo a responsabilidade são dos profissionais policiais, terminando com os posteriores encaminhamentos para a rede sócio-assistencial existente; (b) Dentro do fluxograma do atendimento à tais vítimas, em comparação com os outros Estados da federação analisados neste breve estudo Minas Gerais e Bahia - os profissionais não policiais ficam no final do processo, ou seja, não fazem o papel no acolhimento, deixando tal função à cargo de um profissional de nível médio; logo após feito o registro de ocorrência, as vítimas são encaminhadas para tais profissionais com a finalidade essencialmente "terapêutica". ${ }^{13}$

\section{"O Olhar - Fazer Interdisciplinar" no Âmbito Policial}

A interdisciplinaridade tem sido considerada como componente chave na constituição de muitos campos que envolvem profissionais de diferentes áreas frente a temas e problemáticas pluridimensionais. A crítica à fragmentação das ciências contemporâneas, da pulverização e verticalização dos saberes especializados e de suas implicações, vem sendo construída por várias perspectivas.

Sendo a Delegacia de Polícia um 
campo de atuação onde o Direito positivo está muito impregnado, desde a primeira formação do aparato público de vigilância e de segurança - vale lembrar Foucault (2003, p.68) quando o mesmo expõe sobre a concepção do inquérito, que tornam as especialidades subalternas e auxiliares diante do conhecimento e interpretações das leis, sob o poder magno do Direito. Algumas publicações como Saraleque (1977, p.14) que tratam da segurança pública dizem que tal campo de atuação e intervenção - no caso da Delegacia de Polícia - é um dos aparelhos executores, repressores e ideológicos do Estado, e que faz parte da estrutura do mesmo (vertentes contemporâneas mais mecanicistas do marxismo dentro do campo do Direito). ${ }^{14}$

No campo policial percebe-se uma espécie de imperialismo epistemológico, pois, historicamente, tal espaço sócio-ocupacional fez parte de um dos projetos institucionais não democráticos, que interpelam as identidades sociais “compactas" e não pluralistas. É visto o conflito entre os que denotam o poder no ápice desta hierarquia - os Delegados de Polícia - e os demais policiais subalternos e colaboradores. Nota-se que, com a renovação dos quadros dentro da Polícia Civil, tal conflito tem diminuído, mas ainda é muito presente. ${ }^{15}$

Para prosseguir o estudo, fez-se uma síntese sobre os níveis de cooperação e coordenação possíveis em diferentes espaços sócio-ocupacionais, inspirado na literatura (Japiassu, 1976, p.71; Sá, 1995, p.42; Seiblitz,1995, p.32; Vasconcelos, 2001, p.56). Logo em seguida, faremos algumas relações com outros dados coletados, perante os profissionais policiais e não policiais, inseridos no Programa Delegacia Legal da PCERJ.

Nas definições gerais, temos: (a) As práticas multidisciplinares podem ser caracterizadas por uma gama de campos do saber que se propõem simultaneamente, mas sem fazer aparecer as relações existentes entre eles. Pode-se dizer que há apenas um só nível, múltiplos objetivos e nenhuma cooperação (SEIBLITZ, 1995, p.36);

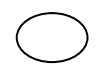

Fonte: Seiblitz (1995) (b) As práticas pluridisciplinares podem ser caracterizadas por uma justaposição de diversos campos do saber situados geralmente em um mesmo nível hierárquico e agrupados em um modo em que existam relações entre elas. É um sistema de um só nível e de múltiplos objetivos. Há cooperação, porém, nenhuma coordenação (SEIBLITZ, 1995, p. 37);

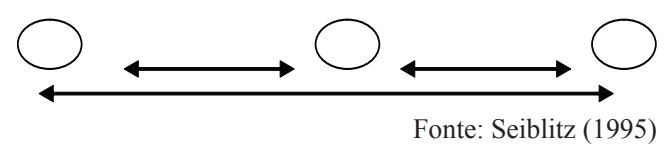

(c) As práticas pluriauxiliares que podem ter sua configuração descrita como a utilização de contribuições de um ou mais campos de saber para o domínio de um deles já existente, que se posiciona como campo receptor e coordenador dos demais. Nesse caso, há uma tendência ao imperialismo epistemológico, descrito, a grosso modo, como um sistema de dois níveis cuja a coordenação e objetivos são hegemonizados pelo campo de saber encampador (VASCONCELOS, 2001, p. 60);

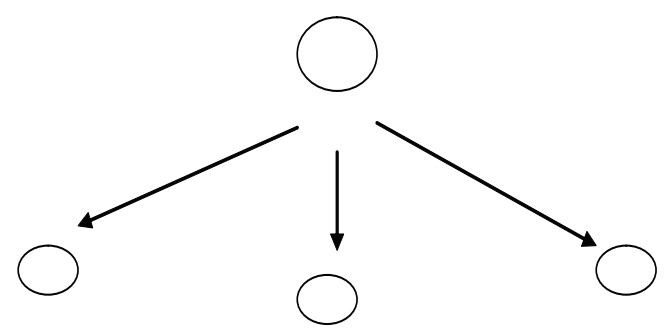

Fonte: Elaboração do próprio autor inspirado segundo a concepção descrita por Vasconcelos(2001)

(d) As práticas interdisciplinares podem ser descritas como interações participativas que incluem a construção e pactação de uma axiomática comum a um grupo de campos de saber conexos, definida no nível hierarquicamente superior, introduzindo a noção de finalidade maior que redefine os elementos internos dos campos originais. Pode-se dizer que tais práticas podem ser configuradas em um sistema de dois níveis e objetivos múltiplos, onde a coordenação procede-se de um nível superior, mas a tendência é de horizontalização das relações de poder (SEIBLITZ, 1995, p. 38);

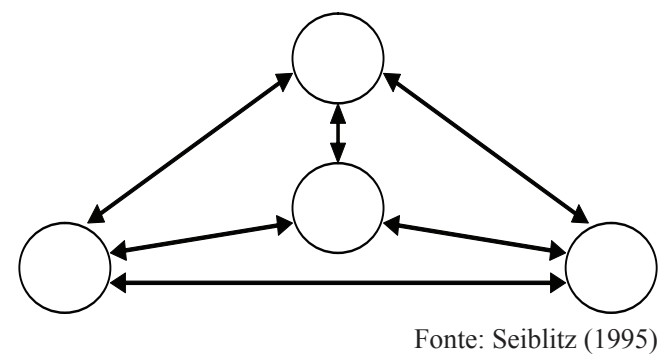

(e) Os campos transdisciplinares podem ser descritos como campos de interação de médio e longo prazo, que pactuam uma coordenação de todos os campos de saberes individuais e interdisciplinares de um campo mais amplo, sobre a base de uma axiomática geral compartilhada. Há a tendência a uma estabilização e criação de um campo de saber com autonomia teórica

${ }^{14}$ Podemos dizer da herança dada por Althusser entre às décadas de 60 a 70, e que influenciou - e muito - às ciências sociais no Brasil na autocracia burguesa que imperou de 1964 a 1985.

${ }^{15}$ Isto é visto na PCERJ - Polícia Civil do Estado do Rio de Janeiro; tal fenômeno nas demais como nos estados de São Paulo, Minas Gerais, Paraná e Bahia. 
e operativa própria. São descritos como sistemas de níveis e múltiplos objetivos, coordenados com vistas a uma finalidade comum dos sistemas com tendências à horizontalização das relações de poder (SEIBLITZ, 1995, p. 38).

Tal “olhar disciplinar" (SÁ, 1995, p. 56) vem da tentativa, não só do GE, mas de um grupo de profissionais comprometidos em solucionar, dinamizar e compartilhar conhecimentos dos mais diversos campos do saber, com a finalidade de alcançar um objetivo em comum. No caso em questão, o objetivo no âmbito policial, é a configuração final do "inquérito ou flagrante fechado", ou seja, o processo do atendimento conter dados da tríade: vítima(s), acusado(s,as) e evidências materiais 16

As evidências materiais são aquelas que dão a concretude e o caráter positivo do Direito Criminal, ou seja, a configuração do objeto penal. Se tais evidências fecham o inquérito policial, isso pode determinar se é preciso ou não de outras verificações investigativas preliminares ${ }^{17}$, e que resulta no auto de prisão em flagrante ${ }^{18}$ e seu subsequente encaminhamento ao Ministério Público e à Vara Criminal correspondente.

Analisando a bibliografia que acerca sobre o tema "interdisciplinaridade", descrita por Vasconcelos (2001, p. 66), Sá (1995, p. 45) e Seiblitz (1995, p.32), observamse que as práticas mais correntes dentro de uma DP são as práticas pluriauxiliares. Tais práticas são as configurações construídas dentro de um espaço sócio-ocupacional onde a investigação inquisidora, a vigilância e o poder estão muito bem articulados, e que se transformam de acordo com as conjunturas apresentadas no cotidiano. As práticas multi e interdisciplinares surgiram nesse contexto, quando o sistema de segurança pública foi colocado em xeque pela sociedade que passou a exigir resultados rápidos $\mathrm{e}$ objetivos. Nessa conjuntura, o sistema abre as portas para novas metodologias de organização do trabalho. ${ }^{19}$

Tais práticas pluriauxiliares são as mais corriqueiras, pois toda a confecção e configuração do inquérito policial estão centradas na figura do Delegado - que detém a palavra final do dueto saber-poder do qual é mandatário - no qual o mesmo "delega" as atribuições e poderes aos seus subalternos hierárquicos. O imperialismo epistemológico, já dito anteriormente, é tão somente a subordinação de outros campos do saber diante de um campo hegemônico que se apropria de suas contribuições. Neste caso, o Delegado se apropria dos outros saberes de seus subalternos -inclusive dos supervisores de atendimento social ${ }^{20}$ - para fechar o inquérito policial em um "pacote" já pré-fabricado e pré-determinado, encaminhado para os canais superiores da justiça. ${ }^{21}$ A relação de poder existe nessa prática, e não existirá uma coresponsabilidade, e sim toda a supremacia e total responsabilidade do saber encampador, ou seja, do Delegado, sem compartilhar com demais saberes abaixo do campo hegemônico já instituído.

\section{"O Olhar - Fazer Interdisciplinar": uma Realidade Pontual.}

Embora a presença do campo

${ }^{16}$ As evidências materiais são aquelas que dão a concretude e o caráter positivo do Direito Criminal, ou seja, a configuração do objeto penal. Se tais evidências fecham o inquérito policial, isto pode determinar se é preciso ou não de outras verificações investigativas preliminares, e que resulta no auto de prisão em flagrante ${ }^{16}$ e seu subseqüente encaminhamento ao Ministério Público e à Vara Criminal correspondente.

${ }^{17}$ Tais procedimentos sem as evidências materiais são denominados como VIP - Verificação Investigativa Preliminar, neste caso o inquérito não está fechado ou concluído, para seu posterior encaminhamento para o MP e para a autoridade judiciária do foro competente.

${ }^{18}$ No auto de prisão em flagrante, o acusado fica na sala de custódia na Delegacia Legal correspondente a circunscrição do delito penal em poucas horas até a sua condução à Casa de Custódia intermediária ou Unidade Penitenciária.

${ }^{19} \mathrm{Com}$ o descrédito do sistema de segurança pública no Estado do RJ, com altas taxas de criminalidade e de pouca resolutividade dos crimes, o Programa Delegacia Legal foi uma das respostas para reverter tal quadro - que está ainda muito longe de ser solucionado.

${ }^{20}$ Há delegados - os que recorrem a tal prática pluri-auxiliar - que desconhecem a atuação dos Supervisores de Atendimento Social. Para os mesmos tal profissional só tem a sua atuação no atendimento ao público apenas. E muitos (não generalizando) depreciam o trabalho deste profissional não policial.

${ }^{21}$ Segundo o MP, o inquérito em "pacote" é aquele que não contém ligação dos fatos com o delito propriamente dito, fazendo com que o mesmo seja questionado e que a lavratura seja refeita na DP de origem. Passando desapercebido pelo MP e pelo Poder Judiciário, pode ser questionada pela defesa do(a) acusado(a) em questão - prática que ocorre bastante. 
hegemônico do Direito positivo já descrito, há casos pontuais vivenciados dentro de uma DP, em que se pode visualizar o "olhar interdisciplinar", retirado de Sá(1995), e apropriado nas discussões entre o profissional não policial $^{22}$ e os demais policiais de uma determinada equipe de plantão, constituída pelo Delegado de Plantão, dois Inspetores de Polícia, dois Oficiais de Cartório e um Investigador de Polícia. Nos casos crescentes e corriqueiros de violência intrafamiliar na região chegada à $\mathrm{DP}$, foram feitas várias reuniões, que foram frutos de conversas ocasionais do delegado com o supervisor de atendimento social (SAS), depois socializadas com os demais profissionais policiais. O objetivo em comum era como lidar, e como fechar os inquéritos de forma mais completa possível e concisa, para que não houvesse impunidade, e que a(s) vítima(s) fosse $(\mathrm{m})$ bem encaminhada(s) aos serviços de referência.

Acoordenaçãodoplantão, tendo a centralidade na figura do delegado, definia apenas os procedimentos e não o resultado, pois, o mesmo deveria ser construído por todos, além de buscar possíveis resoluções ou ramificações. A horizontalização das relações de poder era notório durante tais intervenções, cujo objetivo primordial era a identificação de um axioma em comum, ou seja, o inquérito fechado e sem falhas, com desdobramentos que não ficassem apenas nas muralhas do Direito Penal. A questão da punição legal e a obtenção inquisidora da verdade tornam-se importantes, mas não centrais. A vítima, o seu contexto sócio-familiar, o conhecimento da legislação específica e o sistema de proteção social tornaram-se parte dos saberes construídos por essa equipe. A não re-vitimização destas vítimas também tornou-se ponto central, embora houvesse dificuldades, mas a preocupação era eminente. No caso de vítimas abaixo dos 12 anos de idade, o papel do supervisor de atendimento social (SAS) era de suma importância na confirmação e na coleta dos dados sobre o fato ocorrido.

Este saber construído rendeu resultados expressivos para esta equipe, onde, não só o delegado-coordenador desta edificação- é o responsável pelo inquérito, mas os profissionais policiais e o profissional não policial responsável pelo Atendimento Social - assinam o corpo do documento final que era encaminhado (sem retorno) para o Ministério Público (MP) e à Vara Criminal correspondente.

A experiência interdisciplinar nesta DP era mais recorrente nos casos extremados de violência cometida contra crianças e adolescentes. Nos casos de violência contra a mulher, em sua maioria, não eram resolvidas de forma interdisciplinar já descrita, excetuando nos casos onde a violência era estendida à prole.

\section{"O Olhar - Fazer Interdisciplinar": Relatos Dos Profissionais.}

O sentido deste trabalho sobre o "olhar-fazer interdisciplinar" provocou alguns questionamentos na direção de saber qual o entendimento das equipes sobre a interdisciplinaridade nesse campo uma vez que tudo deve ser pensado e feito de modo a não haver erros. Ameticulosidade e a precisão dos dados colhidos são fatores essenciais para se chegar ao sucesso de uma investigação, o objetivo comum que todos esperam: o inquérito fechado, com as vítimas socorridas e com a imputação penal ou não dos possíveis culpados. Será que estavam tendo o "olhar" e o "fazer", considerando a interdisciplinaridade?

Para alcançar tal intento, seguimos alguns procedimentos metodológicos utilizados: observação não participante, observação participante e grupo focal. Citando Silva \& Milito(1995, p.33), fez-se uma observação não participante. Ir ao 
campo de atuação na DP, despojar-se do olhar viciado nas mesmas direções e do olhar no vazio; despojar-se da pretensão de já saber tudo, já conhecer tudo ou da ansiedade em objetivar ações sem procurar antes entender melhor a realidade. Foi um primeiro mapeamento exploratório do trabalho de campo. Apreender os conflitos visíveis e a correlação de forças no espaço de trabalho.

A observação participante deu-se com abordagens e contatos mais próximos. É a etapa em que normalmente se é abordado antes de abordar. É quando se responde às perguntas dos sujeitos sobre o que se vai querer saber o que se faz ali naquele que é o seu território. Quer saber o que significa esse olhar que se lança sobre ele(s). É o primeiro momento da fala e da escuta, do diálogo por excelência.

Depois da percepção do espaço do campo dentro da DP e de várias experiências de práticas inter no trato da violência doméstica, para prosseguir com o estudo pretendido, fez-se dois grupos focais: uma com a equipe de plantão no qual o supervisor - autor deste trabalho-fazia parte, ea outracom as profissionais não policiais, ou seja, as assistentes sociais que ocupavam o cargo de supervisoras de atendimento social (SAS). O grupo focal, segundo Rizzini, Castro\&Sartor (1999, p.48) é utilizado tanto na pesquisa qualitativa, quanto na quantitativa, para elucidar questões do pesquisador, antes da escolha, formulação e aplicação de outras técnicas de coleta de dados. A organização de um grupo de trabalho focal é útil para que se levante os interesses junto aos sujeitos, acerca de suas expectativas e necessidades em relação ao tema a ser estudado.

Foram feitas quatro reuniões com cada grupo focal - nos horários de plantão na DP -sendo o primeiro com os profissionais policiais, que era constituído por 8 pessoas (sendo 7 policiais civis e o autor deste trabalho), e o outro grupo com as profissionais não policiais - constituídas por uma representante do GE, três supervisoras de atendimento sociale três estagiárias ${ }^{23}$ do programa em questão.

Quatro questões foram propostas nos grupos focais. São elas:

1)O Que Você Sabe Sobre Interdisciplinaridade ?

2) Você Já Teve Experiências Ou Trabalhos E/Ou Investigações Com Outros Profissionais De Outros Saberes E Conteúdos? Comente.

3) O Que Você Sabe Sobre Violência Doméstica?Você Já Atendeu Muitos Casos/Ocorrências? Você Já Trabalhou Com Outros Profissionais Policiais Ou Não?

4) Qual A Importância Que Você Acha Ou Não De Trabalhar Com Outros Profissionais (Sendo Eles Policiais Ou Não) Na Elucidação De Casos E Ocorrências De Violência Doméstica?

Nos dois grupos focais primeiro grupo focal, todos os seus integrantes - profissionais policiais e as "profissionais do Balcão" - responderam e debateram sobre o objeto central desta pesquisa -a “interdisciplinaridade". $\mathrm{Na} 1^{\mathrm{a}}$ pergunta, em que foi questionado se os policiais civis já ouviram sobre o tema central, objeto deste estudo, as respostas chegaram a uma axiomática em comum quanto aos profissionais policiais, como por exemplo, "consenso entre disciplinas", "espaçoonde profissionais de diversas áreas se interagem", ou "união de conhecimentos em torno de um objetivo em comum". Os policiais civis mais novos do corpo da PCERJ estão muito mais familiarizados com o tema que os mais antigos. Alguns policiais inseridos neste estudo (5 dos 7 que participaram no grupo focal) são graduados em cursos de ensino superior ou na área de humanas ou na de saúde, e já tiveram experiências de práticas inter em outros espaços sócio- 
ocupacionais antes de ingressarem à PCERJ.

Quanto às profissionais não policiais, a perspectiva de um trabalho multiprofissional foi bastante evidenciado. As estagiárias desconheciam o tema proposto neste questionamento, e as graduadas reforçam dizendo que só começaram a discutir sobre a prática interdisciplinar em cursos de extensão e especializações. A graduação, muitas das vezes, não aderiu às discussões sobre a interdisciplinaridade, e isto é comum nos cursos na área de humanas, inclusive no Serviço Social. As duas graduadas - SAS - que atuam nas DEAM's demonstraram domínio sobre o tema, além da militância colocada no combate à violência contra a mulher. Também informaram que a centralidade da violência doméstica nas DEAMs exige, e muito, a prática interdisciplinar nos procedimentos de atendimento dentro da DP, mas as experiências ainda são pontuais.

$\mathrm{Na} 2^{\text {a }}$ pergunta, foi questionado sobre a oportunidade de terem tido outras experiências de trabalhos multiprofissionais em investigações policiais - que não precisava ser somentenotratodeviolênciadoméstica. Quanto aos policiais civis, entre os mais novos (4 entre 7 que participaram no grupo focal) no corpo da PCERJ foi colocado que o campo do Direito não responde às questões mais delicadas como o da violência intrafamiliar, e que precisa da complementaridade de outros campos do saber. A maioria teve experiências anteriores em estágios probatórios nas DEAM's integradas ao programa. Entre os mais antigos (com mais de 15 anos na PCERJ), somente há o reconhecimento de outros policiais denominados "peritos" como o médico legista e o perito criminal ${ }^{24}$ propriamente dito. Quanto às "profissionais do Balcão", colocaram experiências de trabalhos multiprofissionais na elucidação de casos na DP - sem que houvesse propriamente casos de violência doméstica. A que atua em uma DP não especializada colocou que nunca teve tal experiência - nem em casos de violência intrafamiliar. As duas que atuam nas DEAMs disseram que nem sempre essa "troca" ocorre da maneira mais enriquecedora, pois os conflitos são constantes. Por mais que estejam lidando com profissionais que têm algum preparo para esse atendimento específico, além da experiência profissional com este perfil de vítima, muitas vezes, as situações são consideradas como de pouco ou menor importância ou se culpabiliza a vítima por estar e manter a relação conflituosa, não levando em consideração os diversos fatores pré-existentes, como por exemplo a dependência, a falta de autoestima e de autoconfiança, que fazem com que a vítima tenha essa postura. Há uma necessidade de ruptura desse descrédito dada à mulher vítima de violência doméstica.

No $3^{\circ}$ questionamento - com os policiais civis - houve vários debates sobre o tema "violência doméstica", mas também de experiências anteriores com o tema e, se já haviam trabalhado com profissionais não policiais. Neste momento, todos - sem exceção, ou seja, os sete policiais civis - colocaram a necessidade de ter um profissional não policial que possua conhecimento aprofundado e especializado sobre o tema, não para ajudar na resolução apenas, mas para somar e complementar com outros campos do saber, necessários para a boa elucidação desses casos. A presença de profissionais policiais formados em áreas diferentes ao do Direito, também é importante na constituição das equipes, segundo todos os policiais presentes neste grupo de discussão.

Quanto ao grupo focal constituído pelas profissionais não policiais, tanto as estagiárias como as graduadas colocaram que o conhecimento sobre o tema não é abrangente e que necessitam de 
reciclagens e aperfeiçoamento para se sentirem mais seguras na sua intervenção. E, além disso, elas só não atuaram no programa de fato no trato da violência intrafamiliar por causa da recusa de muitos policiais civis desqualificarem a sua atuação já dito anteriormente - ficando apenas nos encaminhamentos para a rede de referência, sem um acompanhamento em conjunto dos inquéritos. Algumas colocaram que se sentem como "recepcionistas de luxo", e colocam que o gênero é fator determinante para a "boa ou má" entrada no meio policial.

$\mathrm{Na} 4{ }^{\mathrm{a}}$ pergunta, foi questionadaa importância de se trabalhar juntamente com outros profissionais - policiais ou não - oriundos de vários campos do saber. Além de terem colocado a supremacia imperialista do Direito sobre outras áreas do conhecimento, todos da equipe de policiais colocaram que a renovação nos quadros da PCERJ não só profissionalizou o policial civil, como quebrou o paradigma do modus operandi de fazer uma condução investigatória contando apenas com o direito penal. Também foi colocado que a presença do profissional não policial, além de ter modificado não só o espaço, a correlação de forças ${ }^{25}$ dentro de uma DP; ajudou a humanizar a relação usuário - policial. Eles colocaram a importância dos "profissionais do Balcão" de serem considerados uma ponte - um elo de aproximação entre os usuários dos serviços de uma DP e o policial. No grupo focal das "profissionais do Balcão", todas, sem exceção, colocaram que apesar das dificuldades impostas pelos policiais civis, há tentativas de se implementar uma prática inter aos poucos, mas o trabalho multidisciplinar foi, ainda a única perspectiva alcançada por enquanto. Colocaram também a importância do "Balcão de Atendimento" como responsável pela humanização na comunicação com

\footnotetext{
${ }^{25}$ Tornar o meio policialesco menos autoritário.
}

o usuário, e também na facilidade do acesso a serviços públicos existentes na rede de referência.

\section{Conclusões E Considerações Finais.}

Fecha-se este trabalho, após a exposição sobre as experiências relatadas, não só pelo autor, mas pelos profissionais envolvidos nos casos relatados. Tratou-se da atuação dentro do âmbito policial que, neste estudo, é um espaço em microescala do que o Estado e o meio societário concebem sobre o tema Violência Doméstica. Mesmo notando-se que os profissionais envolvidos possuíam conhecimentos específicos dessa temática dentro dos campos de saber os quais pertencem, o "olhar e o fazer interdisciplinar", não seguiu o seu percurso integral; não se conseguiu construir e resultar um saber novo e autêntico, pois mesmo com todo o apoio do grupo gestor do Programa "Delegacia Legal", a organização e a prática adotadas ainda impedem que os novos caminhos cheguem à sua conclusão. Em casos pontuais e focais, não há a ponte necessária e nem tempo necessário para se fazer o elo para se chegar a este saber novo, embora as experiências, na escala micro, resultaram em avanços importantes, que não podem ser desprezados. O que se pode colocar como principal fator que obstrui o caminho é a presença da velha estrutura arcaica da Polícia Civil, mesmo com a nova perspectiva colocada pelo grupo gestor do Programa já descrita.

\section{Referências Bibliográficas.}

ALMEIDA, GES, MELO,AISC. Interdisciplinaridade: possibilidades e desafios para o trabalho profissional In: Capacitação em Serviço Social e Política Social: Módulo 02: NEAD/ CEAD - UnB, dez/1998.

ALMEIDA, MHT. A relação igualdadeXdesigualdade: um sonho em 
eclipse In: SERRA, R (org.). Trabalho e Reprodução: enfoques e abordagens, PETRES-FSS/UERJ, Cortez Ed., SP, 2001.

ARIÈS, P. A História Social da Criança e da Família, LTC ed., $2^{\mathrm{a}}$ edição, 2000. (Tradução: Dora Flaksman).

CHAUÍ, M. Perspectivas antropológicas da mulher 4 -sobre mulher e violência, Zahar Editores, 1985.

CROMBERG, R.U. Cena incestuosa: abuso e violência sexual, Coleção Clínica Psicanalítica - Casa do Psicólogo, SP, 2001.

DONZELOT, J. A Polícia das Famílias . Graal Ed., $3^{\text {a}}$ ed., São Paulo, 1986.

FORTI, VL., MARCONSI, C. Em tempos neoliberais, o trabalho dos assistentes sociais em cena. In: SERRA, R (org.). Trabalho e Reprodução: enfoques e abordagens, PETRES-FSS/ UERJ, Cortez Ed., SP, 2001.

FOUCAULT, M. Vigiar e Punir: história da violência nas prisões, Ed. Vozes, 27ªed., Petrópolis/RJ, 2003.

GUERRA, VNA. Violência de Pais contra Filhos: a tragédia revisitada, Cortez ed., 4ª ed., São Paulo, 2001.

JAPIASSU, H. Interdisciplinaridade e Patologia do Saber, Rio de Janeiro, Imago, 1976.

MINAYO, M.C.S. A violência social sob a perspectiva da saúde pública. In: Cadernos de Saúde Pública - ENSP/ FIOCRUZ, RJ, 1985.

PONTES, R.N. Mediação: categoria fundamental para o trabalho do assistente social In: Capacitação em Serviço Social e Política Social, mod.4, UnB-CEAD. Brasília-DF, 1999.
RIZZINI, I. , CASTRO, M.R. , SARTOR, C.D. Pesquisando: Guia de Metodologia de Pesquisa para Programas Sociais Série Banco de Dados-6, Ed. Universitária Santa Úrsula, Rio de Janeiro, 1999.

SÁ, J.L.M. (org.). Serviço Social e Interdisciplinaridade: dos fundamentos filosóficos à prática interdisciplinar no ensino, pesquisa e extensão, $2^{\mathrm{a}} \mathrm{ed}$.. Cortez Ed, SP, 1995.

SARALEQUE, F.E., Aspectos Básicos do Serviço Social Criminológico. In: CBCISS nº125, mimeo, 1977.

SEIBLITZ, Z. Três dimensões da noção de interdisciplinaridade. In: Debates Sociais $\mathrm{n}^{\circ} 54 / 55$, CBCISS e Dept $^{\circ}$ de Serviço Social da PUC/Rio, RJ, 1995.

SESP/RJ - Programa Delegacia Legal. Portifólio-DP: Em busca da qualidade. (mimeo), Nova Iguaçu/RJ, 2004.

SILVA, H.R.S. , MILITO, C. Vozes do Meio-Fio: Etnografia . Ed.Relume Damará, Rio de Janeiro, 1995.

VASCONCELOS,E.M.Complexidade e Pesquisa Interdisciplinar: Epistemologia e Metodologia Operativa. Ed.Vozes, Petrópolis/RJ, 2002.

Endereço para Correspondência:

Michael Hermann

Assistente Social pela Universidade Federal de Juiz de Fora - UFJF, Especialista em Violência Doméstica e Urbana pela PUC Rio de Janeiro e Mestrando da Pós - Graduação Strictu Sensu em Políticas Sociais e Cidadania pela Universidade Católica do Salvador (UCSal)- Salvador/BA,

Membro associado da NET- Núcleo de Estudos do Trabalho-PPGPSC/UCSal e Membro do Núcleo de Pesquisa e Estudos sobre Juventude, Identidades, Cidadania e Cultura - PPGPSC/UCSal Email: asmichael@uol.com.br 